\title{
PROBLEMÁTICA SOBRE A AMOSTRAGEM DE DESEMBARQUES COMERCIAIS DE PESCADOS: O ESTUDO DO CASO DA AMOSTRAGEM DO BONITO LISTADO EM ITAJAÍ
}

\author{
H. A. ANDRADE \\ CTTMar - Universidade do vale do Itajaí (FACIMAR/UNIVALI) \\ Rua Uruguai 458, Cx.P. 360, Itajaí, SC - CEP 88.302-202 \\ humber@univali.rsct-sc.br
}

\begin{abstract}
RESUMO
A confiabilidade do cálculo de vários parâmetros populacionais pesqueiros baseados na estrutura de comprimento é dependente da qualidade dos dados obtidos na amostragem. A amostragem de dados provenientes da pesca comercial, tem como vantagem a precisão e o baixo custo, porém pode incluir uma série de vícios. O plano amostral nesse caso, é fundamental para o sucesso dos estudos. Dentro dessa perspectiva, a amostragem de dados de comprimento de bonito listado, proveniente da pesca comercial sediada em Itajaí, é avaliada quanto a sua robustez, qualidade e também para a identificação de problemas existentes. Através de cálculos de erro padrão da média e da amplitude de classes obtidas nas amostras, foi evidenciado que é necessário cerca de 100 medições em cada série ou caixa. As discordâncias entre as distribuições de freqüência obtidas a partir de séries de medidas dentro de uma mesma urna e de caixas provenientes do mesmo porão, indicam que devem ser realizadas mais de uma série de medidas em cada descarregamento. Houveram também discordâncias entre as distribuições de freqüência de comprimento de urnas diferentes, evidenciando a necessidade da realização de pelo menos uma série de medidas para cada urna, cada uma delas com cerca de 100 indivíduos. As variações espaciais e temporais consideráveis na estrutura de comprimento populacional, indicam que os esforço amostral deve ser direcionado para cobrir os desembarques provenientes do maior número de áreas possível em um dado período de pesca.
\end{abstract}

Palavras Chave: Amostragem; Pesca Comercial; Pesca de Vara e Isca-Viva; Bonito Listado; Brasil

\section{ON THE PROBLEMS OF COMERCIAL FISHERY SAMPLING: THE SKYPJACK TUNA FISHERY SAMPLING IN ITAJAÍ (SC) AS A CASE STUDY}

\begin{abstract}
The reliability of several lenght structure-based population parameters depends on the quality of lenght frequency-distributions obtained during fishery sampling. Sampling commercial catches are relatively precise and cheap, however it may produce sistematic errors. Sampling strategy, in this case, is essential for the success of the study. Under this perspective, lenght sampling of the skipjack tuna, landed in Itajaí, Santa Catarina (southern Brazil), by the commercial pole-and-line fishery, was evaluated for robustness, precision and to detect possible bias. The estimation of standard errors and size class range of the samples revealed that a minimum of 100 fish are required to be measured of each series. Desagreements in lenght frequency distributions were observed within the same fish hold and between fish holds. Therefore more than one 100 fish series must be measured in each landing and preferentially from all filled fish holds. In addition temporal and spatial variations of the population structure, indicate that sampling effort each month must cover catches originated from the large number of fishing areas possible.
\end{abstract}

Keywords: Sampling; Commercial Fishery; Pole-and-Line Fishery; Skipjack Tuna; Brazil 
ANDRADE, H.A.: A Problemática sobre a Amostragem de Desembarques Comerciais.

\section{INTRODUÇÃO}

A exatidão dos cálculos de modelos pesqueiros baseados em estrutura de comprimento, e o sucesso das conseqüentes decisões administrativas, depende primordialmente da qualidade dos dados obtidos na amostragem. Portanto, a estruturação de um bom planejamento amostral é fundamental em estudos pesqueiros. A obtenção de amostras pesqueiras é possível via cruzeiros de pesquisa, ou através de amostragem de desembarques da frota comercial. A obtenção de dados através dos desembarques comerciais, tem como grande vantagem o custo muito mais baixo e a maior precisão. Entretanto as amostras provenientes de desembarques comerciais devem tratadas cuidadosamente, pois implicam freqüentemente em dados com vários vícios (ex: a seletividade do artefato de pesca, o fato de que a pesca não é distribuída igualmente na área de ocorrência do recurso, direcionamento sobre um recurso alvo, etc...). Portanto é imprescindível para o uso de dados provenientes da pescaria comercial, 0 conhecimento de todo o processo e funcionamento da pescaria. Dessa forma alguns erros podem ser corrigidos ou pelo menos amenizados, evitando-se interpretações equivocadas dos resultados.

Nos estudos que dependem da estrutura de comprimento e peso da fração populacional capturada, além desses vícios intrínsecos da amostragem comercial, um cuidado especial deve ser direcionado ao momento da amostragem em cada desembarque. O ideal seria a mensuração de todos os indivíduos da espécie de interesse existente em todas as urnas da embarcação. Entretanto ao considerarmos desembarques de populações explotadas comercialmente, obviamente na grande maioria dos casos uma mensuração completa é impossível na prática. Nesse caso uma parcela do total descarregado, deve ser amostrada. Nessa situação, surgem uma série de perguntas sobre os procedimentos a serem tomados. Qual a estraté- gia para a obtenção dos espécimes a serem medidos? Quantos peixes devem ser medidos? É necessário a medição de mais de uma série? Quanto às diferentes urnas, qual deve ser o procedimento?

As amostragens de comprimento devem ser representativas e minimizar as variâncias dos números estimados de peixes desembarcados por classe de comprimento. O cálculo dessas variâncias é na verdade complexo. Entretanto, essas variâncias têm relação com a variância do comprimento médio estimado. Assim, devido a essa relação é possível avaliar a precisão das amostragens, a partir da relação entre tamanho, número de amostras, e as variâncias dos comprimentos médios estimados (Pope, 1956).

Quanto a obtenção dos peixes a serem medidos, as metodologias a serem empregadas dependem basicamente da maneira como é realizada a pescaria, como é acondicionado o pescado a bordo e como é feito o descarregamento. A amostragem dos desembarques de bonito listado que vem sendo realizada nos portos de Itajaí, como caso a ser estudado, foi abordada quanto às questões levantadas acima, para avaliação de sua robustez, qualidade e também para a identificação de problemas existentes.

\section{MATERIAL E MÉTODOS}

\section{Medidas de Comprimento}

Os dados de comprimento utilizados para análise foram as medidas tomadas no descarregamento de três embarcações (D1, D2 e D3) (Tabela 1). Duas delas estiveram pescando em áreas diferentes no mês de março de 1997 (D2 e D3), porém descarregaram no mesmo dia (Tabela 1 e Figura 1). O porão delas é dividido em urnas, porém há uma única abertura no convés o que dificulta a identificação da proveniência do pescado em determinado ponto do descarregamento. Essas urnas sem aberturas individuais no convés são 
Tabela 1: Descarregamentos amostrados e $\mathrm{n}^{0}$ de peixes medidos.

\begin{tabular}{|c|c|c|c|c|c|c|}
\hline Descarregamento & Data & Total & Sistema do & Acondicionamento & \multicolumn{2}{|c|}{ № de Peixes Medidos } \\
\hline \multirow{4}{*}{ D1 } & \multirow{4}{*}{$10 / 06 / 97$} & \multirow{4}{*}{50 ton. } & \multirow{4}{*}{ Esteira } & \multirow{4}{*}{ Urna } & \multirow{3}{*}{ Urna 1} & Série 1- 131 \\
\hline & & & & & & Série 2 - 107 \\
\hline & & & & & & Série 3 - 101 \\
\hline & & & & & Urna 2 & Série 1-91 \\
\hline D2 & $13 / 03 / 97$ & 40 ton. & Caixa & "Buraco" & Caixa 1-116 & Caixa 2 - 129 \\
\hline D3 & $13 / 03 / 97$ & 39 ton. & Caixa & "Buraco" & Caixa 1-87 & Caixa 2 - 90 \\
\hline
\end{tabular}

freqüentemente denominadas de "buracos". O pescado é retirado do porão por meio de balaios, depositado em uma caixa com capacidade para cerca de 100 peixes. Essas caixas são então manipuladas através de empilhadeiras. De cada um desses dois desembarques foram medidos os peixes de duas caixas com um intervalo de tempo de cerca de 30 minutos entre cada caixa.

A terceira embarcação amostrada esteve pescando em junho de 1997 (D3) (Figura 1). Essa embarcação tem o porão dividido em urnas totalmente separadas, de forma que cada urna tem uma abertura individual no convés. Dessa forma nesse descarregamento a identificação da proveniência dos peixes amostrados pode ser feita. $O$ pescado é retirado da urna manualmente pelos pescadores, depositado em uma esteira mecânica colocada no convés que leva o peixe até o píer, onde o mesmo é depositado diretamente em caixas grandes, e estas são então manipuladas através de empilhadeiras. Devido à dimensão e altura da borda da caixa, a medição a partir da mesma era inviável. Portanto os peixes a serem medidos eram obtidos diretamente do porão antes de serem depositados na esteira mecânica. De uma das urnas foram tiradas três séries de peixes para as medidas. De uma segunda urna foi medida mais uma série de peixes (Tabela 1).

\section{Avaliação do Número Mínimo Amostral Necessário, Estatística Geral e Distribui- ções de Freqüência de Comprimento}

Há diversas maneiras de se estimar e avaliar o número mínimo amostral necessário em mensurações realizadas em populações naturais (Sokal \& Rohlf, 1981; Haimovici, 1987; Sparre et al., 1989). Uma das mais simples, e que foi utilizada neste trabalho, é a comparação da amplitude de classes de comprimento amostradas, e erro padrão da estimativa da média, em função do número de indivíduos medidos. Esses cálculos foram realizados para cada caixa separadamente e posteriormente para o total do descarregamento. No caso da embarcação com descarregamento em esteiras, as estimativas foram feitas para cada série da urna, para o total da urna e posteriormente para o total do descarregamento. $\mathrm{Na}$ realização do cálculo para mais de uma série e/ou urna conjuntamente, as medidas foram aleatorizadas quanto a sua ordem, na tentativa de simular uma situação real de um único lote.

Foi feita uma estatística geral simples para cada caixa, série e urna, e posteriormente para o total. É necessário ressaltar que o cálculo das médias foi feito com base nas medições exatas em milímetros, entretanto as modas foram evidenciadas somente após a 
classificação das medidas em distribuições de freqüência de comprimento com classes de 1 $\mathrm{cm}$ de amplitude. Para simplicidade da comparação entre séries, caixas e urnas, as distribuições de freqüência de comprimento são apresentadas em valores percentuais.

\section{RESULTADOS}

\section{Descrição da Pescaria}

A pescaria do bonito listado (Katsuwonus pelamis) no sudoeste do Atlântico Sul é realizada basicamente através da metodologia de pesca de vara e isca-viva. Após deixar o porto a embarcação deslocase para áreas onde seja possível capturar através de cerco peixes de pequeno tamanho (normalmente clupeídeos e engraulídeos) que serão usados como isca viva para atração dos cardumes de bonito listado. A captura da isca é feita com o auxílio de uma panga (pequena embarcação motorizada de casco de ferro) que quando içada fica localizada na popa da embarcação mãe. Após capturada, a isca é acondicionada em tanques que possuem um sistema de circulação. Uma vez capturada a

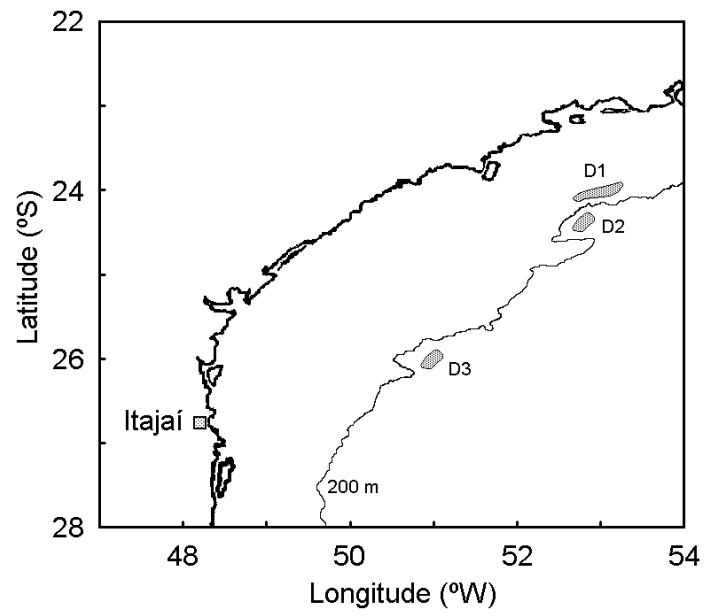

Figura 1: Localização dos descarregamentos amostrados: (D1) Junho de 1997; (D2) Março de 1997; (D3) Março de 1997. isca, os pescadores dirigem-se para as áreas de pesca, procurando por cardumes de bonito listado.

A localização de cardumes é feita na maioria das vezes através da visualização direta, ou de indícios de sua presença, como grandes aglomerações de aves próximo à superfície. Bóias ou qualquer outro objeto flutuante são também verificados quanto a presença de bonito listado ou mesmo de atuns e dourados, outras espécies que também apresentam interesse comercial.

Uma vez localizado o cardume é feita a aproximação da embarcação, com manobras que possibilitem que a mesma fique com 0 cardume encostado em uma das bordas. A partir de então começa a pescaria. Inicialmente é feita a tentativa de atração do cardume através da liberação manual da isca viva. Para aumentar o borbulhamento superficial com a queda das isca, são ligados esguichos de água, tipo "chuveiro", o que torna mais efetiva a atração do cardume. A captura é realizada através de varas (basicamente de bambu), as quais possuem monofilamentos de nylon atados à ponta, com um anzol sem barbela. $O$ anzol tem como peculiaridade um adereço atado a sua haste, normalmente uma pena branca de ave. Este adereço serve também como atrator para o bonito listado. Uma vez fisgado o peixe, o pescador puxa a vara arremessando o peixe para o convés, e uma vez que o anzol não tem barbela, normalmente o peixe é solto no ar e cai sobre o convés, podendo ser distribuído entre as parcelas do porão da embarcação ("buracos"), ou segundo o caso entre as urnas. O pescador retorna então com o anzol para a água, em um processo dinâmico bastante rápido. Na distribuição do peixes entre as urnas não é feita qualquer classificação quanto a tamanho.

É possível que os pescadores permaneçam trabalhando sobre um mesmo cardume por mais de duas horas. Em um determinado momento o cardume dispersa, tornando-se necessária a procura de novos cardumes. Caso a isca termine antes de ter sido 
capturada uma quantidade razoável de pescado (varia com a capacidade de carga da embarcação), os pescadores dirigem-se para áreas costeiras repetem o processo de captura de isca e retornam novamente para as áreas de pesca mais afastadas da costa.

Ao retornar ao porto, o peixe é descarregado através de balaios ou com a ajuda de esteiras motorizadas. A captura é levada para dentro da indústria para o processamento inicial, ou depositada diretamente em caminhões frigoríficos para transporte para outra indústria local ou de outro estado.

\section{Avaliação do Número Mínimo Amostral Necessário}

\subsection{Descarregamento D1}

Para o descarregamento D1, quando atingido cerca de 100 indivíduos medidos, todas as séries já mostraram uma tendência de estabilização quanto a amplitude de classes presente na amostra (Figura 2a). Entretanto houveram diferenças significativas quanto a amplitude de classes entre as séries. Houve uma variação maior entre as séries de medições de uma mesma urna, do que entre urnas diferentes (Figura 2a). A série 1 da urna 1 (U1-S1) foi a que apresentou maior número de classes de comprimento, diferenciando-se das demais. A série única da urna 2 (U2-S1) e a série 2 da urna 1 (U1-S2), mostraram uma amplitude de classes semelhante $(150 \mathrm{~mm})$ enquanto a série 3 da urna 1 (U1-S3), apresentou a menor amplitude de classe. As relações das variações dos erros padrões da estimativa da média entre as séries medidas, mostraram tendências semelhantes às das variações das amplitude de classes (Figura 2b). Quando foram medidos em torno de 50 indivíduos, o erro padrão já caiu substancialmente, apresentando valores sempre inferiores a 7 milímetros. Entretanto, quando medidos em torno de 100 indivíduos a tendência de queda já é muito suave, sendo aparentemente necessário a medição de muitos espé- cimes mais, para que ocorra uma queda significativa do erro padrão da média.

Quando considerado o somatório de todas as séries da urna $1, \mathrm{U} 1(\mathrm{~S} 1+\mathrm{S} 2+\mathrm{S} 3)$, a estabilização da variação da amplitude de classes amostradas ocorre em torno de 120 medições. Quando considerado todas urnas conjuntamente (U1+U2), é aparente também uma estabilização em torno desse número. Entretanto, há um novo salto na amplitude de classes amostradas a partir de 350 medições (Figura 2c). O efeito desse último incremento sobre a estimativa do erro padrão é fraco (Figura $2 d)$. Foi evidente que as variações dos erros padrões de $\mathrm{U} 1(\mathrm{~S} 1+\mathrm{S} 2+\mathrm{S} 3)$ e $(\mathrm{U} 1+\mathrm{U} 2)$ foram muito semelhantes, com tendências de queda muito suaves a partir de 100 medições.

\subsection{Descarregamento $D 2$}

A amplitude máxima de classes presentes na amostra foi semelhante para as caixas 1 e 2 (Figura 3a). Entretanto a estabilização para a caixa 2 ocorreu com um número de medições bem menor do que para a caixa 1 . De qualquer forma, com cerca de 120 medições a amplitude máxima de classes já havia sido alcançada em ambas as caixas. Quando consideradas as duas caixas conjuntamente, a estabilização quanto a amplitude de classes, é alcançada com cerca de 120 medições.

As variações do erro padrão da média para as duas caixas separadas e juntas, foram bastante semelhantes a partir de 50 medições, porém uma tendência mais suave de queda é alcançada somente em torno de 110 medições (Figura 3b).

\subsection{Descarregamento D3}

Assim como para o descarregamento D2, as variações da amplitude máxima de classes presentes na amostra para D3, foram semelhantes para as caixas 1 e 2 (Figura 3c). Entretanto, novamente a estabilização na caixa 2 ocorreu com um número de medições bem menor do que para a caixa 1. A estabili- 
zação para ambas as caixas separadamente ocorreu com cerca de 75 medições, para as caixas somadas a estabilização ocorreu somente com cerca de 120 medições.

As variações do erro padrão da média para as duas caixas separadas e juntas, foram bastante semelhantes, e a tendência mais suave de queda é alcançada em torno de 80 medições (Figura 3d).

\section{Estatística Geral e Distribuições de Fre- qüência de Comprimento}

O descarregamento D3 apresentou um comprimento médio de pescado bem maior do que os demais, enquanto que a primeira urna do D1 foi a que apresentou um pescado de menor comprimento médio (Tabela 2).

Quanto ao erro padrão mínimo alcançado, chama a atenção o erro padrão relati- vamente maior da série 1 da urna 1 (U1-S1), mesmo que nessa série tenha sido medido um número relativamente maior de espécimes. É importante ressaltar que outra série dessa mesma urna (U1-S3) foi a que apresentou o menor erro padrão, apesar de não ter sido medido um número muito grande de espécimes (Tabela 2).

A variância dos valores individuais e o nível de confiança da média, para as distintas séries e caixas medidas, são obviamente proporcionais à amplitude de classes de comprimento existente em cada série e caixa (Tabela 2).

A média não é na verdade um parâmetro que tem um grande significado em distribuições de comprimento de populações naturais de peixes, que freqüentemente não apresentam uma forma gaussiana. Normalmente essas distribuições são multi-modais e
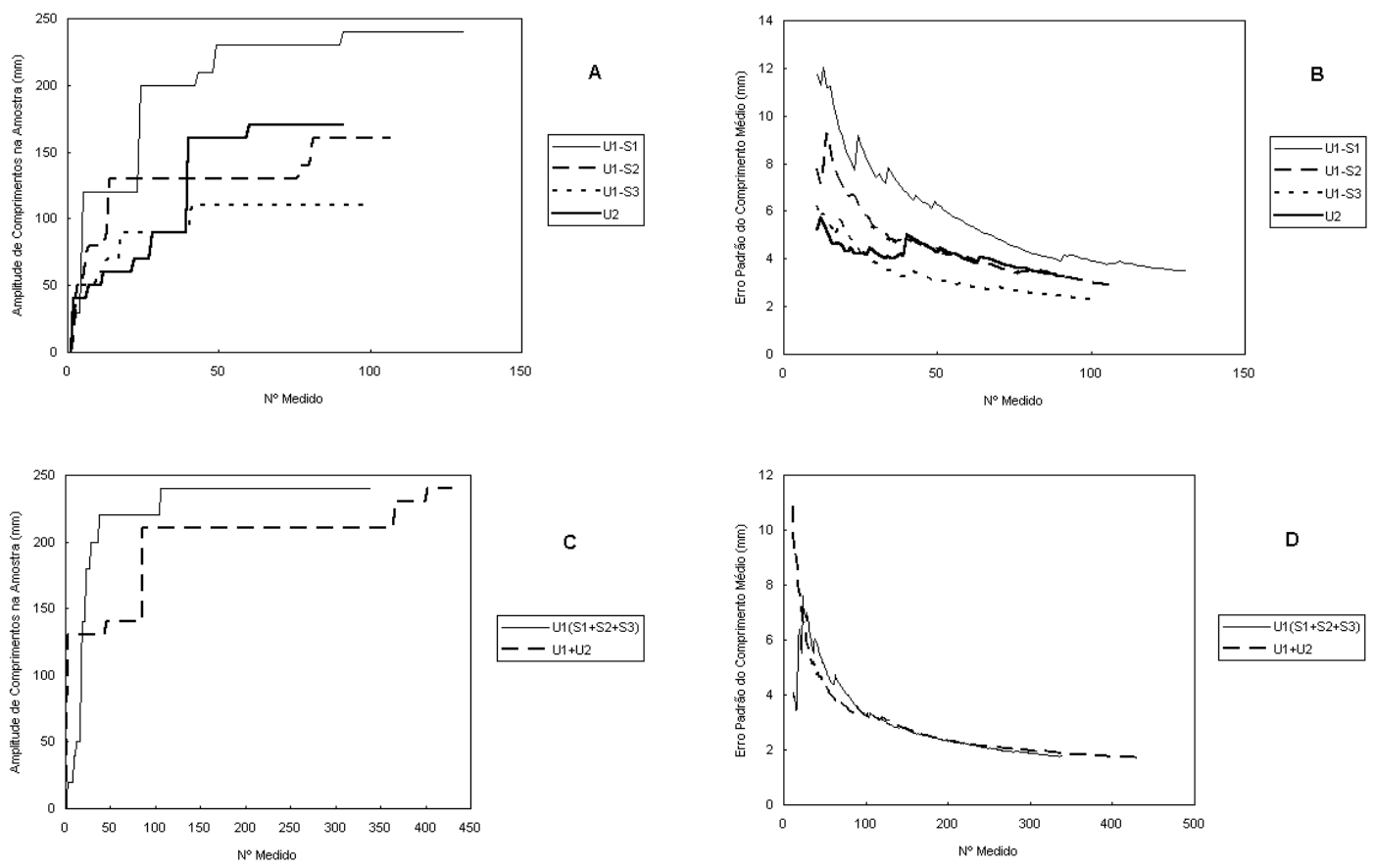

Figura 2: Amostragem do descarregamento D1: (A e B) Amplitude de classes e erro padrão da média para as três séries da urna 1 (U1-S1, U1-S2 e U1-S3) e na série única da urna 2 (U2); (C e D) Amplitude de classes e erro padrão da média para total da urna $1(\mathrm{U} 1(\mathrm{~S} 1+\mathrm{S} 2+\mathrm{S} 3))$ e para as duas urnas conjuntamente $(\mathrm{U} 1+\mathrm{U} 2)$. 
nesse caso as modas tem um maior significado ecológico, representando melhor os grupos etários diferentes em uma população natural. Três séries de medidas apresentaram distribuições nitidamente bimodais, todas elas provenientes do desembarque D1, incluindo as medidas das duas urnas amostradas (Tabela 2 e Figura 4a). O padrão unimodal foi predominante nas distribuições dos desembarques D2 e D3. No entanto as modas das caixas 1 e 2 do D2 são bem diferentes (Figura $4 b)$ enquanto que no desembarque D3 elas foram iguais (Figura 4c).

As modas dos totais por desembarque foram pouco definidas para D1 e D2 (Figuras $5 a$ e b), enquanto que em D3 elas são bem definidas (Figura $5 \mathrm{c}$ ), em virtude da concordância das modas das caixas desse desembarque (Figura 4c). Para o desembarque D1 é mostrada a distribuição de freqüência de comprimento, calculada através do somatório simples das medidas obtidas nas duas urnas indistintamente, e através de uma ponderação, com atribuição igual de peso para as distribuição da urna 1 e da urna 2 (Figura 5a).

As assimetrias das distribuições de freqüência das séries, caixas e dos totais por desembarque foram no geral negativas, somente a série U1-S3 do D1 e a C2 e o total do D2, apresentaram distribuições com assimetria positiva (desviada para a esquerda)(Tabela 2 ).

\section{DISCUSSÃO}

A análise da variação da amplitude de classe na amostra e do erro padrão da média, indica que o número de espécimes medidos atualmente em cada caixa e/ ou série $( \pm 100)$
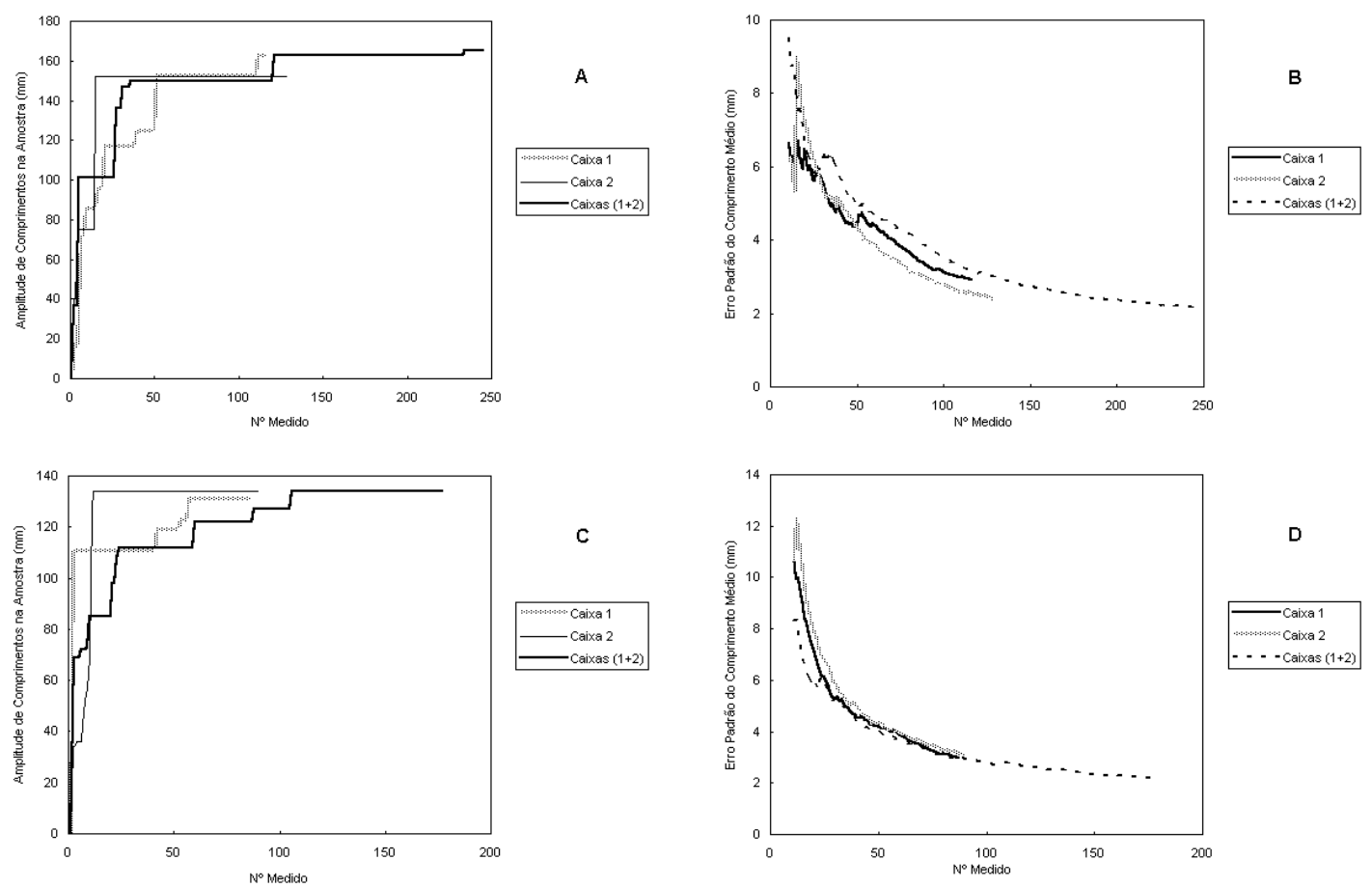

Figura 3: Amostragem dos desembarques D2 e D3: (A e B) Amplitude de classes e erro padrão da média para as duas caixas (C1 e C2) e para o total $(C 1+C 2)$ do descarregamento D2; (C e D) Amplitude de classes e erro padrão da média para as duas caixas $(\mathrm{C} 1$ e $\mathrm{C} 2)$ e para o total $(\mathrm{C} 1+\mathrm{C} 2)$ do descarregamento $\mathrm{D} 3$. 
ANDRADE, H.A.: A Problemática sobre a Amostragem de Desembarques Comerciais.

Tabela 2: Estatística descritiva (dimensões em milímetros) por série, caixa e urna amostrada em cada descarregamento. Se houve dominância de uma moda sobre outra, a principal foi indicada com (1ํ) e a outra como $\left(2^{\circ}\right)$.

\begin{tabular}{|c|c|c|c|c|c|c|c|c|c|c|c|c|}
\hline \multirow[b]{2}{*}{ Parâmetros } & \multicolumn{6}{|c|}{ D1 } & \multicolumn{3}{|c|}{ D2 } & \multicolumn{3}{|c|}{ D3 } \\
\hline & U1-S1 & U1-S2 & U1-S3 & U2 & $\begin{array}{c}\mathrm{U} 1 \\
(\mathrm{~S} 1+\mathrm{S} 2+\mathrm{S} 3)\end{array}$ & Total & S1 & $\mathrm{S} 2$ & Total & $\mathrm{S} 1$ & $\mathrm{~S} 2$ & Total \\
\hline Média & 516,1 & 519,1 & 511,2 & 552,4 & 515,62 & 523,4 & 585 & 552 & 567,61 & 616,8 & 613,1 & 614,92 \\
\hline Erro padrão & 3,5 & 2,9 & 2,3 & 3,2 & 1,8 & 1,7 & 2,9 & 2,4 & 2,2 & 3,0 & 3,2 & 2,2 \\
\hline Mediana & 515 & 515 & 515 & 555 & 515 & 525 & 586 & 548 & 566 & 622 & 615 & 620 \\
\hline Moda & $\begin{array}{l}500\left(1^{9}\right) \\
520\left(2^{9}\right)\end{array}$ & $\begin{array}{l}500 \\
540\end{array}$ & 510 & $\begin{array}{c}570\left(1^{\circ}\right) \\
530-540\left(2^{\circ}\right)\end{array}$ & 500 & $\begin{array}{l}500-510\left(1^{9}\right) \\
530-540\left(2^{9}\right)\end{array}$ & 600 & 540 & 550 & 630 & 630 & 630 \\
\hline Desvio padrão & 39,7 & 29,9 & 23,1 & 30,9 & 32,4 & 35,4 & 31,5 & 27,4 & 33,7 & 27,9 & 30,2 & 29,1 \\
\hline Variância da amostra & 1572 & 894,3 & 531,7 & 955,2 & 1052 & 1255 & 992,9 & 752,5 & 1134,6 & 778,5 & 913,9 & 846,0 \\
\hline Curtosis & 1,69 & 0,08 & $-0,40$ & 1,41 & 1,82 & 0,89 & 0,02 & 0,90 & $-0,48$ & 0,20 & $-0,55$ & $-0,27$ \\
\hline Assimetria & $-0,43$ & $-0,23$ & 0,16 & $-0,83$ & $-0,28$ & $-0,22$ & $-0,20$ & 0,85 & 0,33 & $-0,67$ & $-0,37$ & $-0,51$ \\
\hline Intervalo & 240 & 160 & 110 & 170 & 240 & 240 & 163 & 152 & 165 & 131 & 134 & 134 \\
\hline Mínimo & 385 & 425 & 455 & 435 & 385 & 385 & 492 & 505 & 492 & 541 & 538 & 538 \\
\hline Máximo & 625 & 585 & 565 & 605 & 625 & 625 & 655 & 657 & 657 & 672 & 672 & 672 \\
\hline Número Medido & 131 & 107 & 101 & 91 & 339 & 430 & 116 & 129 & 245 & 87 & 90 & 177 \\
\hline Nível de confiança(95\%) & 6,8 & 5,7 & 4,5 & 6,4 & 3,5 & 3,3 & 5,7 & 4,7 & 4,2 & 5,9 & 6,2 & 4,3 \\
\hline
\end{tabular}

(Tabela 2), é representativo para um dado momento da descarga (Figuras 2 e 3). Houve grande semelhança das variações de amplitude de classe e erro padrão, entre as diferentes séries e caixas (com exceção da U1S1). Apesar disso, há necessidade da medição de mais de uma série e/ou caixa, pois as distribuições de comprimento e modas apresentadas nas medições dentro de um mesmo descarregamento foram freqüentemente diferentes (Tabela 2 e Figuras 4 e 5). Uma exceção para essa tendência foi o descarregamento D3, para o qual as distribuições de freqüência obtidas para as caixas 1 e 2 foram semeIhantes (Figura 4c). Entretanto, considerando as diferenças quanto as modas na maioria das amostras em um mesmo descarregamento, é obviamente mais seguro tomar a decisão em campo de medir mais de uma série e/ou caixa.

O desembarque D2 exemplifica um erro claro do que pode ocorrer com a medição de uma única série amostral. Nesse caso, a medição unicamente da primeira caixa (C1), levaria a uma sub-estimação de indivíduos mais jovens dominantes na segunda caixa (C2) (Figura $4 \mathrm{~b}$ ), os quais, quando consideradas as duas séries, mostraram ser o grupo mais abundante no desembarque (Figura 5b). Vícios como esse introduzidos pela amostragem podem implicar por exemplo em erros de cálculos baseados na estrutura de comprimento (ex: avaliação do crescimento através de progressão modal, e cálculo da mortalidade pelo decaimento no número de indivíduos segundo o comprimento).

Outra questão importante diz respeito ao cálculo da estrutura de comprimento total a partir de séries de medidas tomadas de diferentes urnas e/ou buracos. Para discussão tomemos como exemplo o caso do desembarque $\mathrm{D} 1$, onde foram medidas três séries de uma urna e uma série de outra urna (Tabela 2 e Figura 4a). Se na retirada dos peixes da esteira, não houvesse conhecimento sobre a proveniência dos mesmos ( $\mathrm{n}^{\circ}$ da urna), a distribuição de freqüência do total capturado, seria calculada através de somatório simples das medições das quatro séries. Nesse caso seria obtido uma estrutura de comprimento 
com duas grandes modas amplas em 500/510 e 530/540 (Figura $5 a$ - linha pontilhada). Entretanto, esse procedimento é errado caso o total em peso armazenado nas duas urnas seja semelhante. Nesse caso as distribuições de freqüência total da urna 1 e da urna 2 tem
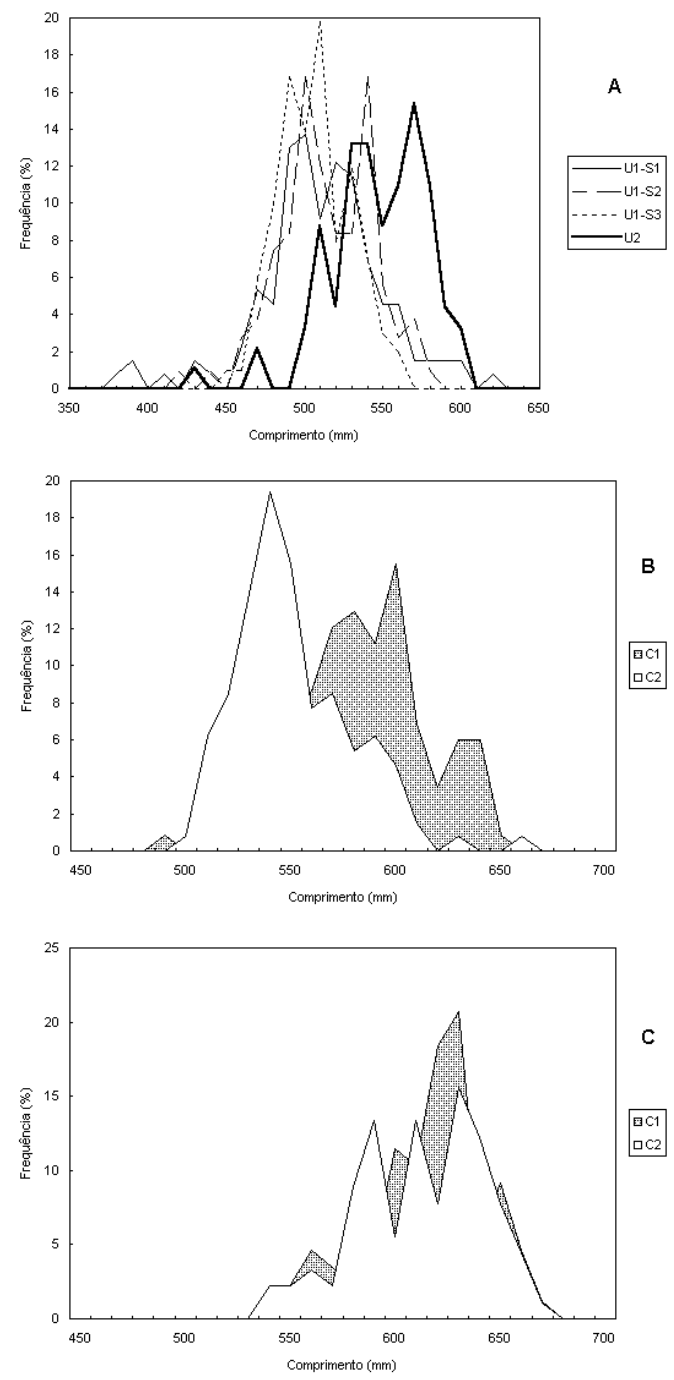

Figura 4: Distribuições de frequência de comprimento obtidas nas amostragens: (A) Três séries da urna 1 (U1S1, U1-S2 e U1-S3) e série única da urna 2 (U2) do descarregamento D1; (B) Duas caixas (C1 e C2) do descarregamento D2; ( C) Duas caixas (C1 e C2) do descarregamento D3. um mesmo peso quanto a representatividade do total capturado pela embarcação. Portanto o procedimento correto seria calcular a freqüência percentual da urna 1 (somatório das três séries de medidas) e da urna 2, e a partir dessas duas distribuições de freqüência, calcular a estrutura de comprimento para o total descarregado (Figura 5a - linha contínua). No exemplo do descarregamento D1, esse procedimento evidenciaria a presença de uma terceira moda em $520 \mathrm{~mm}$, ainda que de importância secundária (Figura 5a). Novamente no caso de vícios desse tipo, erros poderiam ocorrer em análises da estrutura de comprimento.

Além de problemas de ordem prática na obtenção da amostra a ser medida no momento do descarregamento, deve ser considerado ainda as implicações do processo pesqueiro na produção de vícios e erros nos dados comerciais. Teoricamente uma amostragem ótima de uma população natural requer uma amostragem aleatória que permita a descrição exata da estrutura natural existente. Entretanto a pesca comercial certamente não pode ser considerada um processo de amostragem aleatória. Há vários tipos de vícios nos dados provenientes da pesca comercial: (a) os pescadores procuram por áreas de maior abundância dos recursos, e portanto os dados não são representativos para a área total ocupada pelo estoque; (b) os artefatos de pesca são em sua totalidade seletivos de alguma forma e portanto a captura não representa exatamente a estrutura de comprimento natural da população. Além desses dois vícios gerais intrínsecos de qualquer pescaria comercial, há uma série de outros vícios mais específicos de cada pescaria. Assim para o uso de dados provenientes da captura comercial, é imprescindível um bom conhecimento de todo o processo e funcionamento da pescaria, o que permite amenizar ou corrigir vícios, e evitar interpretações equivocadas dos resultados.

O fato de não haver uma classificação por tamanho por parte dos pescadores na di- 
visão dos peixes entre as urnas, indica aparentemente que não haveria necessidade de uma amostragem estratificada do descarregamento. Entretanto, as diferenças encontradas entre séries e urnas são um indício da necessidade de uma amostragem estratificada. Essa estratificação em várias séries ou urnas, é na verdade imprescindível em virtude da "classificação natural por tama-
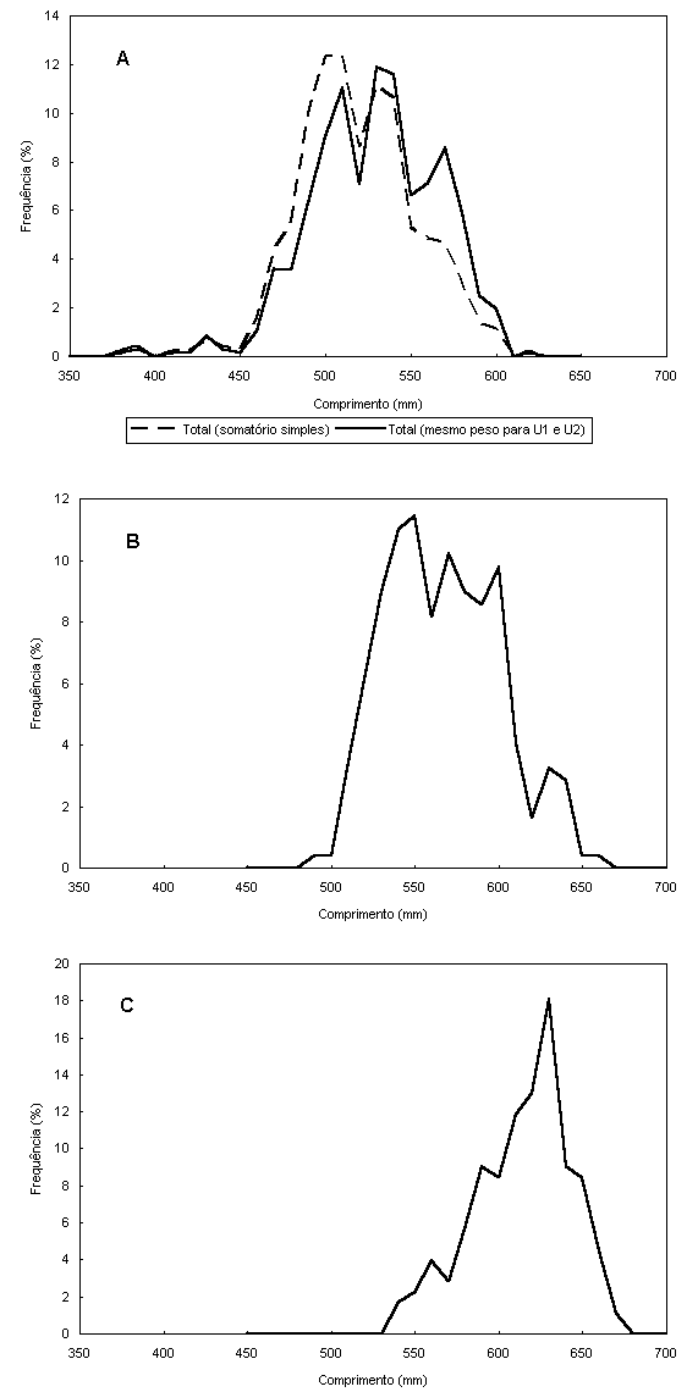

Figura 5: Distribuição de frequência total de cada descarregamento amostrado: (A) Descarregamento D1; (B) Descarregamento D2; (C) Descarregamento D3. nho" derivada do comportamento de formação de cardumes com peixes de comprimento semelhantes.

O bonito listado, assim como a grande maioria das espécies pelágicas, tem a tendência de formação de cardumes. Assim, os indivíduos não se encontram uniformemente distribuídos na área ocupada pelo recurso. Os cardumes de peixes pelágicos, reconhecidamente apresentam uma tendência a serem compostos por peixes de comprimento semeIhante (Pope, 1977; Sparre et al., 1989). Dessa forma em um cardume não estão representados em proporção real todos os comprimentos de peixes existentes na população total. Uma vez que a pescaria é realizada através da abordagem de cardumes individuais pela embarcação, conseqüentemente, a composição de comprimento obtida em cada pescaria não representa realmente a composição de comprimento da população total. Na grande maioria dos casos a embarcação acaba por trabalhar sobre mais de um cardume por viagem. Entretanto, obviamente ainda assim não é obtida em uma viagem uma captura representativa de toda a área de ocupação do recurso.

O efeito da composição de comprimento do cardume, é provavelmente uma das causas para que a maioria das distribuições de comprimento obtidas tenham apresentado uma assimetria negativa (desvio para a direita) (Tabela 2). Normalmente em populações naturais, espera-se uma tendência de assimetria positiva (desvio para a esquerda) para as distribuições de freqüência de comprimento. Essa assimetria é explicada por que em populações de peixes há uma tendência natural de haver um maior número de indivíduos mais jovens, e de que haja um decaimento desse número em função da idade (ou comprimento). Outro fator que pode ter também contribuído para as assimetrias negativas dominantes é a seletividade do artefato de pesca. Não está descartada a possibilidade de menor representatividade dos indivíduos menores, em função do tamanho do an- 
zol, resultando em distribuições desviadas para a direita, com um efeito semelhante ao descrito como fenômeno de Lee (Lee, 1912). Entretanto, a questão deve ser mais especificamente estudada para esclarecimento.

$\mathrm{Na}$ interpretação dos dados obtidos na pesca do bonito listado, um aspecto que não deve ser desconsiderado é o caráter migratório da espécie, que realiza grandes deslocamentos sistemáticos ao longo do ano no sudoeste do Atlântico sul (Andrade, 1996 a). Essas migrações implicam em uma grande complexidade da variação temporal da estrutura de comprimento da população, com constantes ingressos e egressos de grupos de peixes com comprimento modais diferenciados (Andrade, 1996 b). Uma discussão detalhada da problemática do uso de dados de estrutura de comprimento de espécies migratórias, para estudos pesqueiros é apresentada em Sparre et al. (1989).

Uma questão relacionada a amostragem de comprimento de recursos que ocupam grandes áreas, com grande capacidade migratória e ainda com uma distribuição não uniforme na área ocupada, é ressaltada pela comparação das distribuições de freqüência obtidas nos três descarregamentos. Os descarregamentos D1 e D2, apesar de serem provenientes de embarcações que estiveram pescando na mesma área (Figura 1), apresentaram distribuições de freqüência de comprimento muito diferentes (Figuras $5 a$ e b). Já os descarregamentos D2 e D3, apesar de serem provenientes de embarcações que estiveram operando no mesmo período (Tabela 1 e Figura 1), também apresentaram distribuições de freqüência de comprimento muito diferentes (Figuras $5 b$ e c). Os resultados indicam que podem haver grandes variações temporais da distribuição de freqüência de comprimento em uma mesma área, e também espaciais em um mesmo período. Portanto a amostragem deve ser cuidadosa e um grande esforço deve ser feito para cobrir os desembarques provenientes do maior número de áreas possível em um dado período de pesca.

\section{CONCLUSÕES}

A medição de cerca de 100 indivíduos é suficientemente representativa em termos de erro padrão da média ou obtenção de informação acerca de todas as amplitudes de classes presentes em uma caixa ou em dado instante da amostragem. Entretanto houve diferenças grandes quanto as modas das distribuições de freqüência entre séries de uma mesma urna. Dessa forma é aconselhável a realização de mais de uma série de medições de não menos do que 100 peixes cada uma. As diferenças entre as composições de urnas diferentes são significativas, e se possível é aconselhável também a realização de pelo menos uma série de medidas em cada urna.

Há variações espaciais e temporais consideráveis na estrutura de comprimento populacional, dessa forma o esforço amostral deve ser direcionado para cobrir os desembarques provenientes do maior número de áreas possível em um dado período de pesca.

\section{AGRADECIMENTOS}

Aos colegas da equipe de amostragem de pescado.

\section{REFERÊNCIAS BIBLIOGRÁFICAS}

Andrade, H. A. 1996. Distribuição, Abundância Relativa e Migração do Katsuwonus pelamis (Scombridae) em Relação à Temperatura Superficial do Mar e à Dinâmica Oceanográfica na Costa Sudeste-Sul do Brasil. Tese de Mestrado, Universidade do Rio Grande.

Andrade, H. A. 1996. Análise Crítica da Distribuição e Abundância Relativa do Bonito 
Listado (Katsuwonus pelamis) e dos Conhecimentos Atuais sobre a Desova no Sudoeste do Atlântico Sul Ocidental: Uma Hipótese para a Relação entre a Migração e o Ciclo de Vida. Ecossistemas Costeiros: Do Conhecimento à Gestão - $3^{\text {a }}$ Reunião Especial da SBPC. Universidade Federal de Santa Catarina.

Haimovici, M. 1987. Estratégia de Amostragem de Comprimentos de Teleósteos Demersais nos Desembarques da Pesca de Arrasto no Litoral Sul do Brasil. Atlântica 9(1):65-82.

Lee, R. M. 1912. An Investigation into the Methods of Growth Determination in Fishes. Cons. Explor. Mer, Publ. de Circonstance. no. 63.
Pope, J. A. 1956. An Outline of Sampling Techniques. Rapp. P. V. Réun. Cons. Perm. Int. Explor. Mer., 140:11-20, Part 1 Pope, J. G. 1977. Collecting Fisheries Assessment Data. In: J. A. Gulland (Ed.). Fish Population Dynamics. John Wiley e Sons Ltd., Inglaterra, 63-82 p.

Sokal, R. R. \& Rohlf, J. F. 1981. The Principles and Practice of Statistics in Biological Research. São Francisco, W. H. Freeman \& Company. $859 p$.

Sparre, P.; Ursin, E. \& Venema, S. C. 1989. Introduction to Tropical Fish Stock Assessment. FAO.Fish.Tech.Pap. (306/1): $429 \mathrm{pp}$. 